\title{
Article \\ Corona Discharge Characteristics under Variable Frequency and Pressure Environments
}

\author{
Pau Bas-Calopa ${ }^{1}$ (D) Jordi-Roger Riba ${ }^{1, *(\mathbb{D})}$ and Manuel Moreno-Eguilaz ${ }^{2}$ (D) \\ 1 Electrical Engineering Department, Universitat Politècnica de Catalunya, 08222 Terrassa, Spain; \\ pau.bas@upc.edu \\ 2 Electronics Engineering Department, Universitat Politècnica de Catalunya, 08222 Terrassa, Spain; \\ manuel.moreno.eguilaz@upc.edu \\ * Correspondence: jordi.riba-ruiz@upc.edu; Tel.: +34-937-398-365
}

Citation: Bas-Calopa, P.; Riba, J.-R.;

Moreno-Eguilaz, M. Corona

Discharge Characteristics under Variable Frequency and Pressure Environments. Sensors 2021, 21, 6676. https://doi.org/10.3390/s21196676

Academic Editor: Manuel José Cabral dos Santos Reis

Received: 15 September 2021

Accepted: 5 October 2021

Published: 8 October 2021

Publisher's Note: MDPI stays neutral with regard to jurisdictional claims in published maps and institutional affiliations.

Copyright: (C) 2021 by the authors. Licensee MDPI, Basel, Switzerland. This article is an open access article distributed under the terms and conditions of the Creative Commons Attribution (CC BY) license (https:/ / creativecommons.org/licenses/by/ $4.0 /)$.

\begin{abstract}
More electric aircrafts (MEAs) are paving the path to all electric aircrafts (AEAs), which make a much more intensive use of electrical power than conventional aircrafts. Due to the strict weight requirements, both MEA and AEA systems require to increase the distribution voltage in order to limit the required electrical current. Under this paradigm new issues arise, in part due to the voltage rise and in part because of the harsh environments found in aircrafts systems, especially those related to low pressure and high-electric frequency operation. Increased voltage levels, high-operating frequencies, low-pressure environments and reduced distances between wires pose insulation systems at risk, so partial discharges (PDs) and electrical breakdown are more likely to occur. This paper performs an experimental analysis of the effect of low-pressure environments and high-operating frequencies on the visual corona voltage, since corona discharges occurrence is directly related to arc tracking and insulation degradation in wiring systems. To this end, a rodto-plane electrode configuration is tested in the $20-100 \mathrm{kPa}$ and $50-1000 \mathrm{~Hz}$ ranges, these ranges cover most aircraft applications, so that the corona extinction voltage is experimentally determined by using a low-cost high-resolution CMOS imaging sensor which is sensitive to the visible and near ultraviolet (UV) spectra. The imaging sensor locates the discharge points and the intensity of the discharge, offering simplicity and low-cost measurements with high sensitivity. Moreover, to assess the performance of such sensor, the discharges are also acquired by analyzing the leakage current using an inexpensive resistor and a fast oscilloscope. The experimental data presented in this paper can be useful in designing insulation systems for MEA and AEA applications.
\end{abstract}

Keywords: more electric aircraft; electrical discharges; visual corona; corona extinction voltage; variable frequency; low pressure

\section{Introduction}

More electric aircrafts (MEAs) allow for reducing weight [1], fuel consumption, greenhouse gas emissions, operation and maintenance costs and boosting overall system efficiency when compared with conventional aircrafts [2]. However, engineers are facing important challenges due to the increased voltage levels MEAs require, the increase in the power density and the $\mathrm{d} v / \mathrm{d} t$, or the reduction in distances between electrical wires, thus increase the likelihood of electric arc occurrence [3,4] with the consequent safety risks.

Jet aircrafts typically fly at altitudes between 33,000 and 42,000 feet $(10,000 \mathrm{~m}$ to $12,800 \mathrm{~m}$ ) [5], thus operating under harsh environmental conditions. Some electric and electronic aircraft systems operate in unpressurized zones [6], so electric and electronic aircraft systems must be designed to operate under a broad range of pressures, in the range $1 \mathrm{~atm}$ to $0.15 \mathrm{~atm}[7]$.

The development of MEA and AEA systems is accompanied by a rise of the distribution voltage levels, since for a given power, the lower the current, the higher the voltage, and vice versa. However, according to Paschen's law, when operating at higher 
voltage levels and reduced pressure, there is risk of partial discharges (PDs) and electric breakdown [8], the inception voltages of such discharges being below the ones found at sea level $[9,10]$.

Direct current (dc) distribution systems of current aircrafts are operated at $28 \mathrm{~V}, 270 \mathrm{~V}$ $( \pm 135 \mathrm{~V})$ or $540 \mathrm{~V}( \pm 270 \mathrm{~V})$, whereas alternating current (ac) distribution systems are operated at $230 \mathrm{~V}$ or $115 \mathrm{~V}$ phase voltage with variable or wide frequency (typically $320-800 \mathrm{~Hz}$ ) [11], or $230 \mathrm{~V}$ or $115 \mathrm{~V}$ phase voltage with constant frequency $(400 \mathrm{~Hz})[12,13]$. In AEA, voltage levels in the range 2 to $3 \mathrm{kV}$ seem advantageous [13]. It is believed that ac distribution systems in the voltage range between 0.6 and $2 \mathrm{kV}$ lead to wiring systems with less weight, reduced power losses and higher efficiency. However, above $2 \mathrm{kV}$, additional insulation requirements add extra mass to the system, thus needing careful analysis [13]. Because of the need of more electrical power, next generations MEA aircrafts will probably raise the distribution voltage above $1 \mathrm{kV}[14,15]$. According to NASA, future aerospace systems can operate at voltages up to $20 \mathrm{kV}$ (designed for $40 \mathrm{kV}$ ), with high-frequency operation $(400 \mathrm{~Hz}$ to $4000 \mathrm{~Hz})$ [16]. The combination of low pressure, high voltage and highoperating frequencies stresses insulation systems [13], with the consequent degradation risk due to partial discharge and arc tracking occurrence $[17,18]$ because electrical discharge inception voltages can be much lower than those at sea level [1].

Wiring issues in aircrafts due to electrical discharges and arc tracking leading to insulation degradation have caused catastrophic accidents [13]. Different insulation materials have been proposed to combat insulation degradation $[19,20]$. This is of paramount importance because MEA and AEA make an increasing use of electric and electronic apparatus and devices, so polymer insulation materials are inevitably exposed to harsh and varying environments. Thus, care must be taken in selecting appropriate insulating materials since reliability is an issue [21]. Before electric breakdown occurrence, partial discharges (PDs) appear, PDs being discharges that do not entirely channel the insulation between two electrodes [22]. They are roughly classified as internal discharges, external discharges and corona discharges. Although short duration PDs are usually harmless, when they persist over time, they tend to generate important insulation damage in polymeric materials because PDs can produce a partially conductive path or track on the insulation outer surface, thus favoring the flow of an electric current and ultimately arc tracking activity or even complete electrical breakdown [23]. Arc tracking occurring in organic (polymeric) insulation systems, damages the polymer material, which shifts from insulating to conductor because of the tremendous thermal shocks due to the electron bombardment generated by the electrical discharge [24]. This effect also breaks the polymeric chains and degrades the insulation, generating conducting carbon tracks, which reduce the insulating properties of the polymer surface and promote electrical breakdown [25], fire hazard [26] and explosions [27], even at very low voltage [28]. Atmospheric pressure, applied voltage, supply frequency and geometry are dominant variables to determine corona discharge inception and extinction levels.

It is worth noting that reliability and safety are key points in aircraft systems. To design reliable aircraft insulation systems, it is necessary to have a deep knowledge of the conditions leading to a corona [6] as a function of environmental pressure and supply frequency, because if these conditions are not controlled, they can lead to damaging effects, including arc tracking and electrical breakdown [2]. To better understand the effect of low pressure and supply frequency on the development of electrical discharges, it is imperative to run extensive test plans. Due to the difficulty to operate under low-pressure environments and using high-voltage generators with adjustable frequency, there is a lack of experimental data obtained under conditions compatible with aeronautic environments. This paper aims to contribute in this field. In addition, some of the studies are focused to analyze the disruptive spark breakdown $[29,30]$, but non-uniform gaps can lead to corona inception and extinction voltages much lower than those required to ignite disruptive or breakdown discharges. 
To analyze the effect of low-pressure environments jointly with the effect of the supply frequency, a rod-to-plane electrode configuration is tested in the $20-100 \mathrm{kPa}$ and $50-1000 \mathrm{~Hz}$ intervals, these ranges account for the wide range of pressure and frequencies found in aircraft applications.

The detection of partial discharges and arcing activity in aircrafts in the very early stage is a problem that remains unsolved, so there is an imperious need to develop sensor systems to solve this important safety problem. Although there are several sensors that potentially can be applied to detect electrical discharges such as PD detection, antennas to detect electromagnetic noise and radio interference voltage, or acoustic sensors, they are too complex or are severely affected by the noise found in aeronautic applications. In addition, these methods do not directly allow to locate the discharge points. Therefore, this paper focus on the visible-UV light emitted by the electrical discharges because this method offers immunity to noise, while allowing to locate the discharge points.

It is known that the corona effect generates visible (mainly blue) and ultraviolet (UV) light [31]. Thus, by using optical sensors sensitive to these spectral regions, it is possible to detect the corona discharges in the early stage [2]. A corona can also be detected by means of other methods, which are usually more complex, such as optical spectrophotometers [32], audible noise meters [33], PD and radio interference voltage (RIV) detectors [34] or UHF sensors [35]. However, the simpler and straightforward way to locate the discharge point is by using visible-UV imaging sensors. Therefore, to determine the conditions leading to a corona, the corona extinction voltage is determined by using a low-cost high-resolution CMOS imaging sensor. This sensor is sensitive to the visible and near ultraviolet spectral ranges, and the discharge points are identified from the images generated by the CMOS sensor, as well as the intensity of the discharge, thus offering high sensitivity, simplicity low-cost measurements and immunity to electromagnetic noise. Results attained with the imaging sensor are compared with those obtained by analyzing the leakage current. Experimental data presented in this paper can be useful to design insulation systems for future MEA and AEA applications, thus ensuring the reliability of aircraft insulation systems for electrical and electronic circuits.

Specific objectives of this research work include determining the combined effect of pressure and frequency on visual corona and specifically on corona extinction voltage (CEV) for aeronautics applications using a low-cost CMOS imaging sensor, and to compare the sensitivity of such sensor with that of a leakage current sensor.

The paper is organized as follows. Section 2 details the experimental setup to generate a variable frequency high voltage and the instrumentation used, as well as the sensors used to detect the corona extinction voltage. The experimental results are presented in Section 3, whereas Section 4 discusses the results attained. Finally, the conclusions of the paper are developed in Section 5.

\section{Experimental Setup}

Corona experiments were performed inside a pressurized chamber that allows reducing the pressure from $100 \%$ to $20 \%$ of the pressure at sea level, i.e., from $100 \mathrm{kPa}$ to $20 \mathrm{kPa}$ approximately, covering the altitude/pressure interval of commercial jet liners. The low-pressure chamber is composed of a stainless-steel cylindrical container (diameter $=130 \mathrm{~mm}$, height $=375 \mathrm{~mm}$ ) with a sealed methacrylate lid to allow the wireless imaging sensor to transmit the long-exposure photographs to a computer placed outside the low-pressure chamber, as displayed in Figure 1c. The pressure is regulated using a vacuum pump (1/4 HP, $0.085 \mathrm{~m}^{3} / \mathrm{min}$, Bacoeng BA-1, Bacoeng, Suzhou, China) and a manometer (76 mmHg, $\pm 2.5 \%$, Bacoeng, Suzhou, China). Experiments were conducted at a constant room temperature of $25{ }^{\circ} \mathrm{C}$. The humidity effect was not studied but limited to below $25 \%$ during the experiments. 


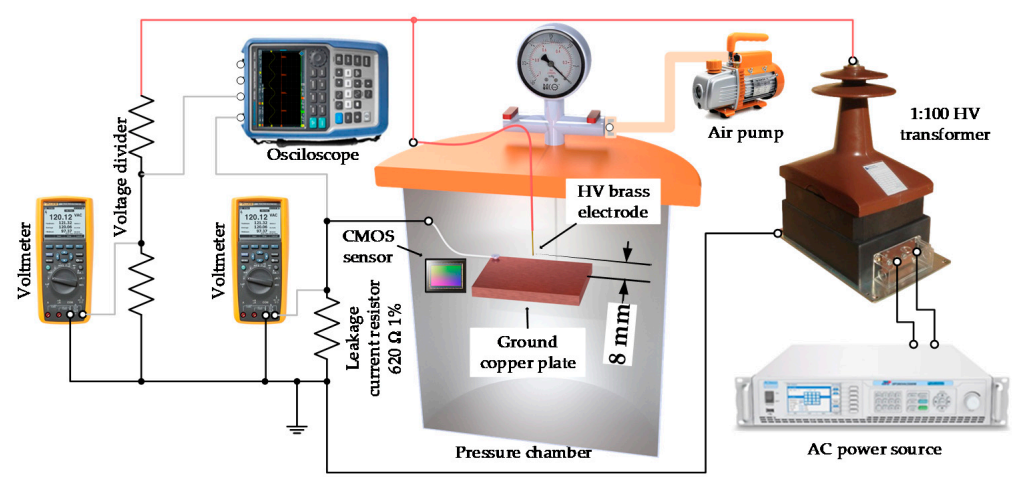

(a)

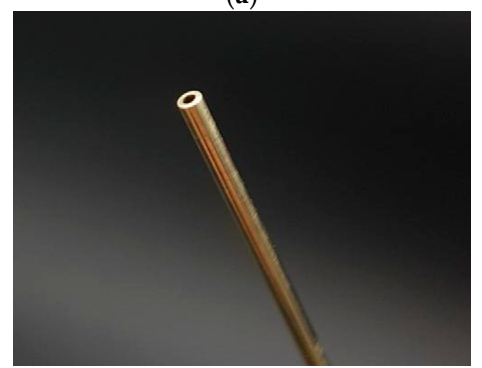

(c)

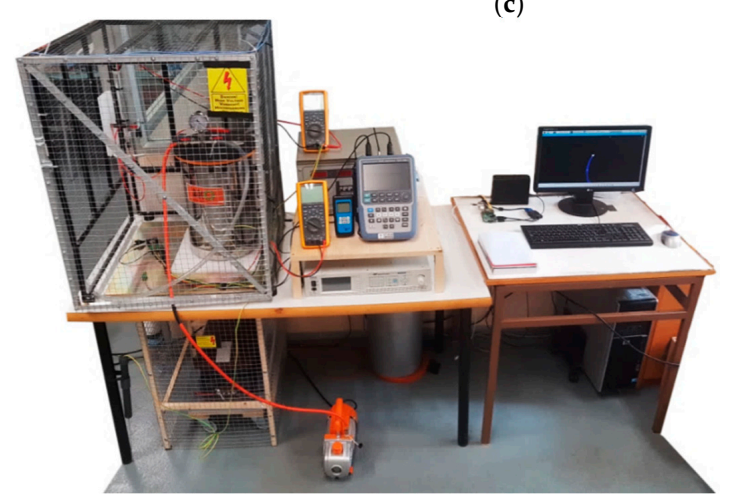

(e)

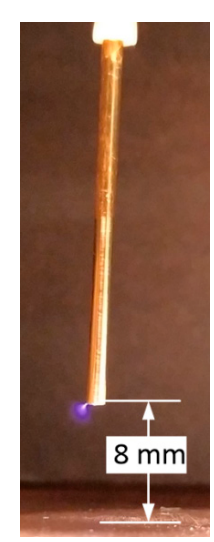

(b)

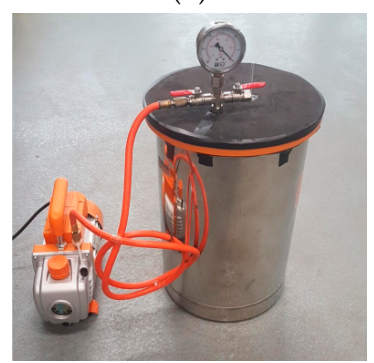

(d)

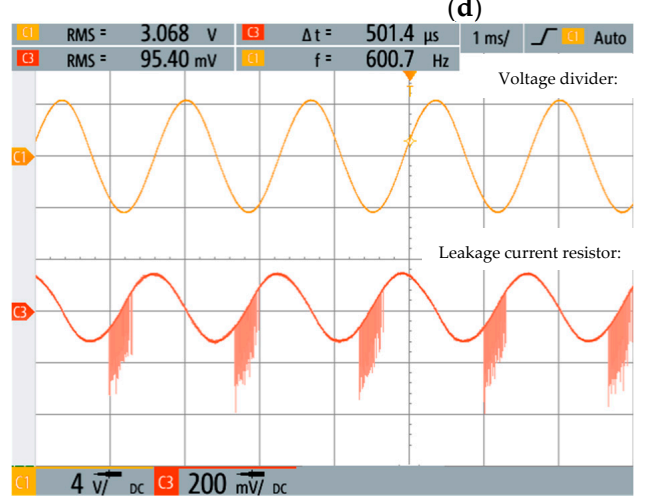

(f)

Figure 1. Experimental setup. (a) Sketch of the experimental setup and the instrumentation used in the high-voltage tests at variable pressure, frequency and voltage; (b) photograph of the rod-to-plane electrode used in the experiments; (c) detail of the tip of the electrode; (d) low-pressure chamber; (e) photograph of the experimental setup including the low-pressure chamber; (f) snapshot of the oscilloscope used to detect corona activity connected to the terminals of the leakage current resistor.

The applied voltage and supply frequency were regulated by means of a SP300VAC600W programmable ac source $(600 \mathrm{~W}, 0-300 \mathrm{~V}, \pm 0.1 \mathrm{~V}, 15-1000 \mathrm{~Hz}, \mathrm{APM}$ Technologies, Dongguan, China) following the IEC61000-4-14 standard. A high-voltage instrument transformer (single-phase, turns ratio 1:100, maximum voltage $36 \mathrm{kV}, 600 \mathrm{VA}, \mathrm{VKPE}-36$, Laboratorio Electrotécnico, Cornellà de Llobregat, Spain) was connected to the output of the SP300VAC600W programmable ac source to step up the output voltage provided by this source.

A voltage divider with a voltage ratio of 1000:1 was used to measure the high voltage at the output of the high-voltage transformer, so that the load voltage was measured with a calibrated true-RMS voltmeter (0-1000 V RMS, 0.4\%, 0-10 A, Fluke 289, Fluke, Everett, WA, USA).

The rod-to-plane gap is composed of a MBT5M brass tube (Albion Alloys, Poole, UK) with outer and inner diameters of $\varnothing=1.5 \mathrm{~mm}$ and $\varnothing=0.8 \mathrm{~mm}$, respectively. The tip of the electrode was placed at a height of $8 \mathrm{~mm}$ above a grounded flat copper plane. A rod-to-plane arrangement was used in this work because this geometry is among the reference gaps used in high-voltage applications [36], thus allowing the generation of 
PDs. The tip was cut with a hacksaw for metals and polished with a metal grinding wheel (fine grain $220 \mathrm{~g}, 2800 \mathrm{rev} / \mathrm{min}$ ). This geometry was chosen in order to generate a corona before arc appearance under the conditions analyzed in this work (20-100 kPa, $50-1000 \mathrm{~Hz}, 25{ }^{\circ} \mathrm{C}$, humidity $<25 \%,<6 \mathrm{kV}$ ) being compatible with the dimensions of the low-pressure chamber.

The experimental corona extinction voltage (CEV) values shown and analyzed in Section 3 are measured by the means of two detection methods. The first method is based on visual corona tests, a corona representing a pre-arc condition in its very early stage before obvious damage in the insulation can be appreciated. To detect the visual corona phenomenon and locate the discharge area, a high-resolution low-cost back-illuminated CMOS imaging sensor (sensor size $8.0 \mathrm{~mm}$, cell size $0.8 \mu \mathrm{m} \times 0.8 \mu \mathrm{m}, 8000 \times 6000$ pixels, 48 Mpixels, 30 frames/second, lens focal $17.9 \mathrm{~mm}$, quad Bayer filter array, images in raw format, IMX586, Sony, Tokyo, Japan) was used, because back-illuminated CMOS sensors are sensitive to visible and UV light [37]. To increase the sensitivity of the measurements, long-exposure pictures were taken for 32s in manual focus mode, selecting an ISO of 400. This is a low-cost sensor that allows for locating corona discharge regions, as well as quantifying the intensity of the discharges, thus easing maintenance tasks. This sensor also enables reducing the costs and complexity of the instrumentation while offering excellent measurement sensitivity and accuracy. Due to a special arrangement of the photodiodes, back-illuminated CMOS imaging sensors allow capturing more light compared with conventional CMOS sensors, thus performing better under low-light conditions, particularly in the UV spectrum $[37,38]$.

To determine the existence of a corona in the images taken by the CMOS sensor, they were first converted to grayscale (rgb2gray function in Matlab ${ }^{\circledR}$ ). Next, the mean value of the pixels of a selected window centered near the corona focus was calculated and compared with the mean value of the pixels from the rest of the image. If the first value is greater than the second by $5 \%$, it is assumed that there is a corona. This simple processing approach is quite immune to the effect of external light (partial darkness).

The second method is based on measuring the leakage current. In this case the sensing system consists of a $620 \Omega \pm 1 \%$ low-inductance resistor connected in series between the ground copper plate and the laboratory electrical ground. The leakage current from the discharges produces a voltage drop across the resistor that was monitored and registered with a fast digital insulated oscilloscope (5GSa/s, $0-1000 \mathrm{~V}, 0.5 \%+0.05 \%$ voltage range, RTH1004, Rohde \& Schwarz, Munich, Germany) equipped with two RT-ZI10 passive voltage probes $\left(500 \mathrm{MHz}, 1 \mathrm{kV}, 10: 1, \mathrm{R} \& \mathrm{~S}{ }^{\circledR}, \mathrm{R} \& \mathrm{~S}\right.$, Munich, Germany).

Corona appearances in the leakage current is seen as peaks superimposed in the current waveform. Therefore, by using a peak detection algorithm (based on the findpeaks function of $\left.\mathrm{Matlab}^{\circledR}\right)$ it is easy to differentiate between corona and no corona conditions.

\section{Experimental Results}

This section details the experimental results obtained by using the setup and instrumentation detailed in Section 2.

\subsection{Visual Corona Photographs Taken with the Back-Illuminated CMOS Sensor}

In order to describe the effects of frequency and pressure on corona discharges, longexposure photographs (32 s exposition time, RGB mode, ISO 400, manual focus, automatic white balance) were taken using the setup detailed in Section 2 . The discharges were performed in the 20-100 $\mathrm{kPa}$ range in increments of $20 \mathrm{kPa}$ and for different frequencies $(50 \mathrm{~Hz}$, $200 \mathrm{~Hz}, 400 \mathrm{~Hz}, 600 \mathrm{~Hz}, 800 \mathrm{~Hz}$ and $1000 \mathrm{~Hz}$ ). Some of the long-exposure photographs are shown in Figure 2, which show the effects of pressure and frequency on the visual corona discharges. It is noted that the voltage levels corresponding to the photographs in Figure 2 are higher than the CEV values to facilitate a good description of the discharge patterns. It is noted that at low pressure, specifically around $20 \mathrm{kPa}$, care must be taken 
when increasing the voltage level, because there is very little difference between the CEV value and the voltage level at which complete breakdown occurs.

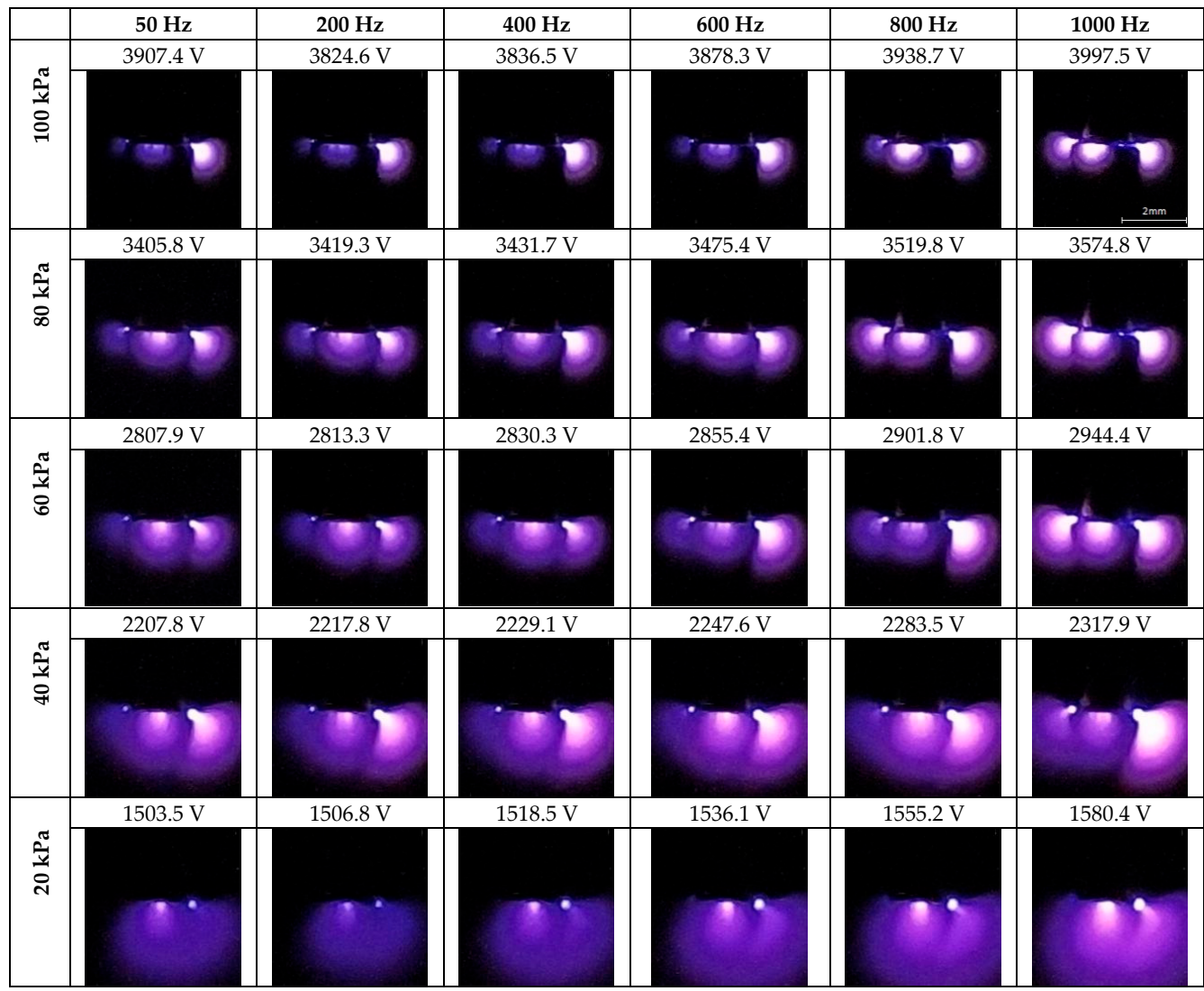

(a)
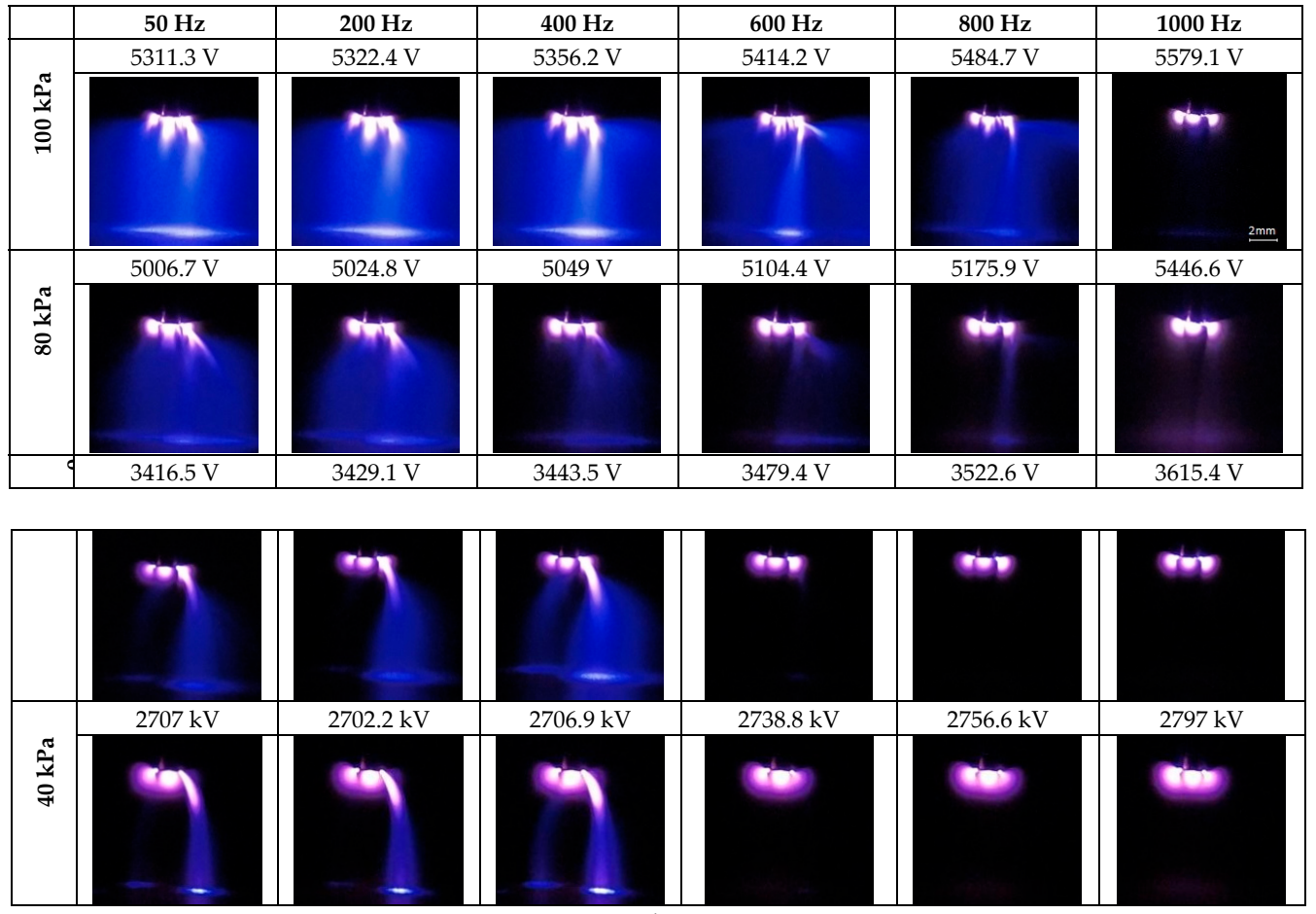

(b)

Figure 2. Long-exposure images taken with the back-illuminated CMOS sensor. (a) Negative ac corona discharges. (b) Positive ac streamer corona discharges. 
Figure 2a shows negative corona discharges before streamers of positive corona appear. The major visual effect is due to the pressure change. At high pressures, corona discharges appear in several spots or "beads" and the active region of ionization is relatively small and well-defined. As pressure decreases, the active region slightly expands and becomes more diffuse, while the number of corona spots reduces. Figure $2 \mathrm{a}$ also shows that the supply frequency has very little visual effect on the distribution of the corona discharges.

Figure $2 \mathrm{~b}$ shows positive corona discharges superimposed with negative discharges, the last ones appearing at lower voltages. According to the images included in this figure, the streamers become more localized and ultimately develop into fewer beams of light $(650 \mu \mathrm{m} \pm 100 \mu \mathrm{m}$ in diameter, measured from the images) as pressure decreases. Figure $2 \mathrm{~b}$ also shows that the density of positive streamers also reduces when the supply frequency increases. It can also be observed that in some cases, for a given pressure, there is a maximum frequency from which streamers are not formed, and a further voltage increase may be followed by electrical breakdown.

\subsection{Obtained Corona Extinction Voltages (CEV)}

This section describes the experimental CEV results attained when analyzing rod-toplane gap geometry, as described in Figure $1 \mathrm{~b}$. To obtain the CEV value, the voltage is progressively increased from $0 \mathrm{kV}$ until identifying corona activity, this point corresponds to the corona inception voltage (CIV). Next, the voltage is increased by about $10 \%$ and slowly reduced until the corona effect extinguishes. The last point is where a corona manifest corresponds to the corona extinction voltage (CEV), i.e., the minimum voltage value where corona activity can be found.

Figure 3 summarizes the process to determine the CEV value. This process was repeated three times for each measurement, and these values were annotated.

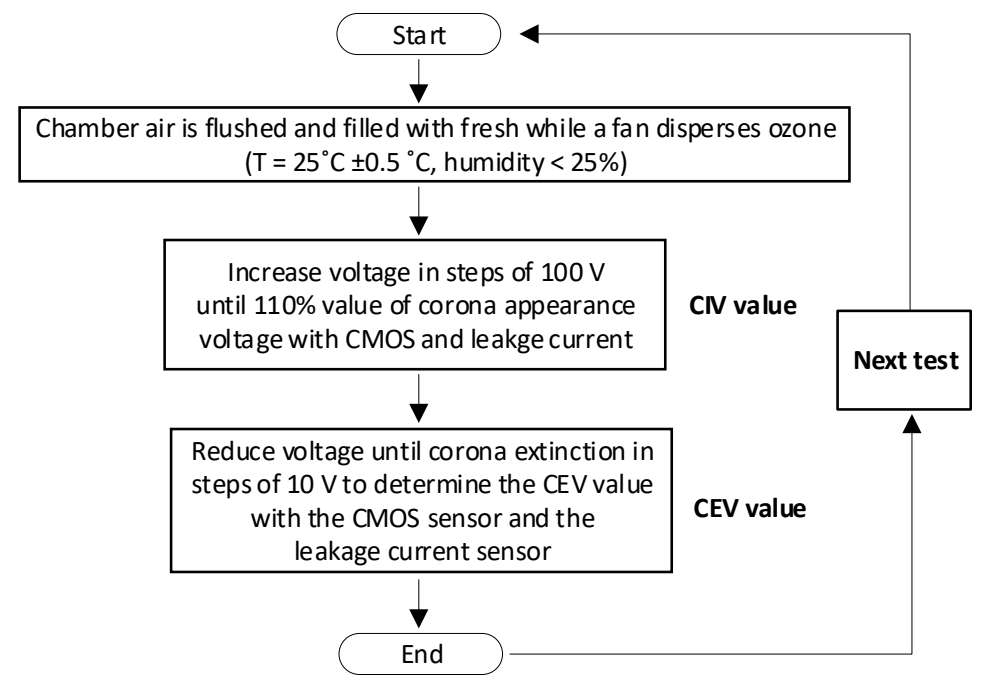

Figure 3. Procedure to determine the value of the corona extinction voltage (CEV).

To avoid the CEV value to be influenced by ozone formation, the atmospheric air in the low-pressure chamber was completely replaced in each test.

Table 1 summarizes the tests performed for each condition (pressure range 20-100 kPa, frequency range $50-1000 \mathrm{~Hz}$ ). 
Table 1. Tests performed (three consecutive repetitions each test).

\begin{tabular}{cc}
\hline Pressures & Frequencies \\
\hline $100 \mathrm{kPa}$ & $50,200,400,600,800,1000 \mathrm{~Hz}$ \\
$80 \mathrm{kPa}$ & $50,200,400,600,800,1000 \mathrm{~Hz}$ \\
$60 \mathrm{kPa}$ & $50,200,400,600,800,1000 \mathrm{~Hz}$ \\
$40 \mathrm{kPa}$ & $50,200,400,600,800,1000 \mathrm{~Hz}$ \\
$20 \mathrm{kPa}$ & $50,200,400,600,800,1000 \mathrm{~Hz}$ \\
\hline
\end{tabular}

The voltage amplitude was increased with discrete steps of $100 \mathrm{~V}$ consisting of a ramp with a standard $1 \mathrm{~V} / \mathrm{ms}$ rate. To determine the CEV value, the voltage was decreased with steps of $10 \mathrm{~V}$ at a rate of $-1 \mathrm{~V} / \mathrm{ms}$.

Table 2 summarizes the CEV values obtained by using the CMOS imaging sensor according to the experimental setup shown in Figure $1 \mathrm{~b}$ when analyzing different frequencies $(50 \mathrm{~Hz}, 200 \mathrm{~Hz}, 400 \mathrm{~Hz}, 600 \mathrm{~Hz}, 800 \mathrm{~Hz}$ and $1000 \mathrm{~Hz})$ and different pressures (100 kPa, $80 \mathrm{kPa}, 60 \mathrm{kPa}, 40 \mathrm{kPa}$ and $20 \mathrm{kPa}$ ).

Table 2. Experimental results corresponding to the rod-to-plane electrode geometry. CEV versus environmental pressure and supply frequency.

\begin{tabular}{|c|c|c|c|c|c|c|c|c|}
\hline Pressure & Test & Sensor & $50 \mathrm{~Hz}$ & $200 \mathrm{~Hz}$ & $400 \mathrm{~Hz}$ & $600 \mathrm{~Hz}$ & $800 \mathrm{~Hz}$ & $1000 \mathrm{~Hz}$ \\
\hline \multirow{7}{*}{$100 \mathrm{kPa}$} & \multirow{2}{*}{ Test 1} & Camera & 3761.5 & 3817.1 & 3784.0 & 3792.0 & 3659.9 & 3579.1 \\
\hline & & Leakage current & 3723.2 & 3788.1 & 3754.5 & 3792.0 & 3659.9 & 3579.1 \\
\hline & \multirow{2}{*}{ Test 2} & Camera & 3802.3 & 3781.0 & 3826.3 & 3899.8 & 3798.5 & 3732.3 \\
\hline & & Leakage current & 3774.4 & 3781.0 & 3826.3 & 3835.9 & 3798.5 & 3732.3 \\
\hline & \multirow[b]{2}{*}{ Test 3} & Camera & 3800.7 & 3819.6 & 3807.1 & 3795.8 & 3843.2 & 3779.7 \\
\hline & & Leakage current & 3763.9 & 3800.5 & 3786.8 & 3774.7 & 3843.2 & 3779.7 \\
\hline & Average & & 3788.2 & 3805.9 & 3805.8 & 3829.2 & 3767.2 & 3697.0 \\
\hline \multirow{7}{*}{$80 \mathrm{kPa}$} & \multirow{2}{*}{ Test 1} & Camera & 3382.9 & 3414.8 & 3410.6 & 3441.2 & 3341.8 & 3146.4 \\
\hline & & Leakage current & 3326.5 & 3377.3 & 3410.6 & 3430.5 & 3341.8 & 3146.4 \\
\hline & \multirow{2}{*}{ Test 2} & Camera & 3367.0 & 3398.1 & 3412.6 & 3424.6 & 3358.8 & 3272.4 \\
\hline & & Leakage current & 3348.2 & 3379.1 & 3373.0 & 3404.0 & 3358.8 & 3272.4 \\
\hline & \multirow[b]{2}{*}{ Test 3} & Camera & 3385.4 & 3377.7 & 3412.9 & 3415.1 & 3358.1 & 3271.9 \\
\hline & & Leakage current & 3329.1 & 3359.3 & 3393.4 & 3404.2 & 3358.1 & 3271.9 \\
\hline & Average & & 3378.4 & 3396.9 & 3412.1 & 3427.0 & 3352.9 & 3230.2 \\
\hline \multirow{7}{*}{$60 \mathrm{kPa}$} & \multirow{2}{*}{ Test 1} & Camera & 2757.9 & 2774.2 & 2761.2 & 2763.5 & 2791.7 & 2689.5 \\
\hline & & Leakage current & 2719.8 & 2736.0 & 2742.6 & 2742.2 & 2781.3 & 2688.1 \\
\hline & \multirow{2}{*}{ Test 2} & Camera & 2798.5 & 2842.9 & 2861.9 & 2868.7 & 2873.7 & 2813.1 \\
\hline & & Leakage current & 2778.4 & 2823.8 & 2842.3 & 2837.2 & 2851.0 & 2813.1 \\
\hline & \multirow{2}{*}{ Test 3} & Camera & 2853.7 & 2918.9 & 2901.8 & 2909.8 & 2916.8 & 2837.4 \\
\hline & & Leakage current & 2815.5 & 2851.7 & 2862.4 & 2889.6 & 2916.8 & 2837.4 \\
\hline & Average & & 2803.4 & 2845.3 & 2841.7 & 2847.3 & 2860.7 & 2780.0 \\
\hline \multirow{7}{*}{$40 \mathrm{kPa}$} & \multirow[b]{2}{*}{ Test 1} & Camera & 2255.6 & 2267.0 & 2270.0 & 2270.7 & 2274.6 & 2254.3 \\
\hline & & Leakage current & 2198.5 & 2248.1 & 2270.0 & 2249.5 & 2274.6 & 2254.3 \\
\hline & \multirow{2}{*}{ Test 2} & Camera & 2266.1 & 2315.4 & 2330.7 & 2333.9 & 2366.7 & 2354.2 \\
\hline & & Leakage current & 2227.7 & 2296.3 & 2330.7 & 2333.9 & 2366.7 & 2354.2 \\
\hline & \multirow[b]{2}{*}{ Test 3} & Camera & 2246.4 & 2316.4 & 2321.5 & 2313.3 & 2322.5 & 2308.0 \\
\hline & & Leakage current & 2246.4 & 2297.3 & 2321.5 & 2313.3 & 2322.5 & 2308.0 \\
\hline & Average & & 2256.0 & 2299.6 & 2307.4 & 2306.0 & 2321.2 & 2305.5 \\
\hline \multirow{7}{*}{$20 \mathrm{kPa}$} & \multirow[b]{2}{*}{ Test 1} & Camera & 1468.8 & 1520.2 & 1522.6 & 1529.0 & 1526.7 & 1529.8 \\
\hline & & Leakage current & 1449.3 & 1520.2 & 1522.6 & 1529.0 & 1526.7 & 1529.8 \\
\hline & \multirow{2}{*}{ Test 2} & Camera & 1374.7 & 1443.1 & 1444.3 & 1426.4 & 1439.3 & 1458.0 \\
\hline & & Leakage current & 1355.2 & 1443.1 & 1444.3 & 1426.4 & 1439.3 & 1458.0 \\
\hline & \multirow[b]{2}{*}{ Test 3} & Camera & 1450.2 & 1474.0 & 1463.6 & 1488.5 & 1552.0 & 1629.1 \\
\hline & & Leakage current & 1450.2 & 1474.0 & 1463.6 & 1488.5 & 1552.0 & 1629.1 \\
\hline & Average & & 1431.2 & 1479.1 & 1476.8 & 1481.3 & 1506.0 & 1539.0 \\
\hline
\end{tabular}


For a better analysis, the results presented in Table 2 are potted in Figure 4.

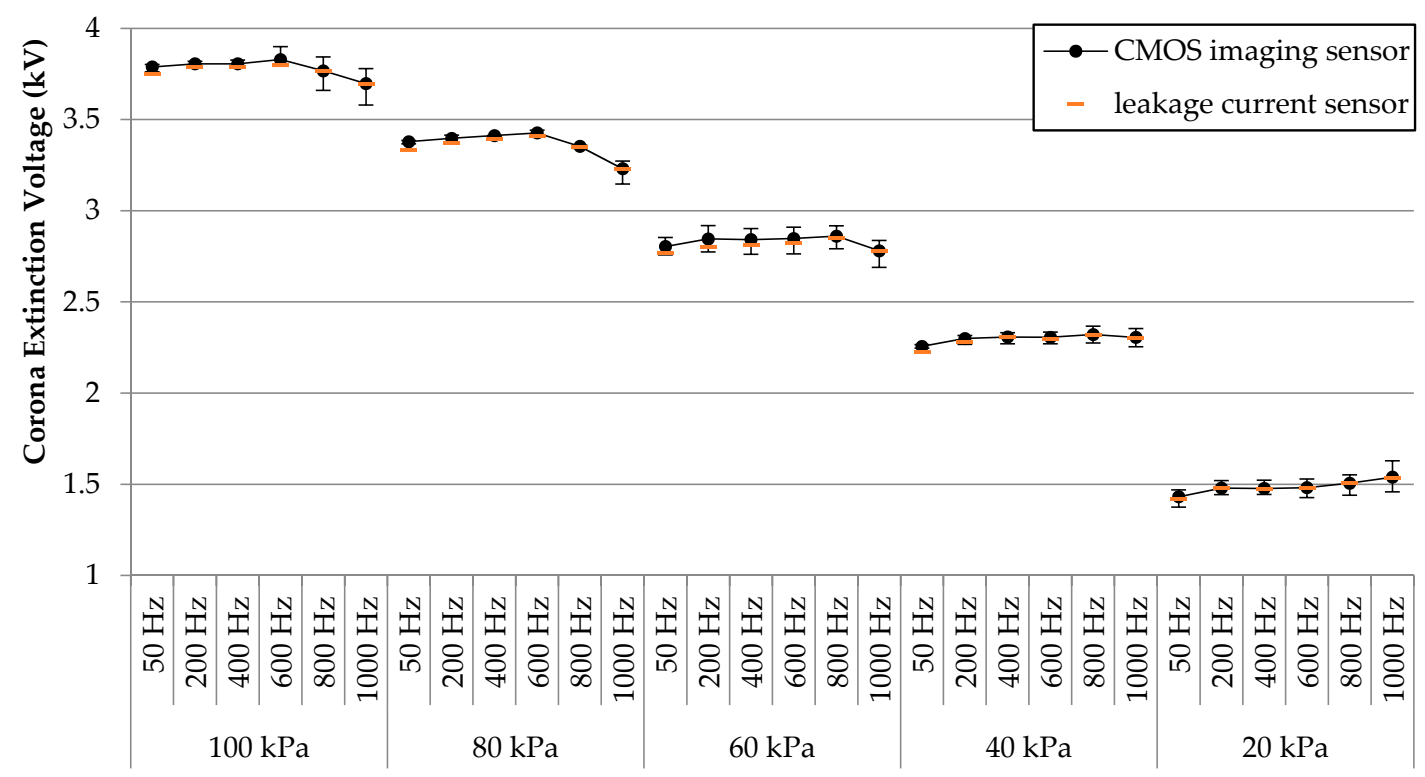

Figure 4. Experimental results of the rod-to-plane electrode geometry. CEV values $(\mathrm{kV})$ versus pressure (kPa) and supply frequency $(\mathrm{Hz})$. Results from the imaging sensor and the leakage current sensor (resistor) were plotted together.

Results in Figure 4 show that when analyzing the rod-to-plane electrode geometry, the effect of frequency in the range $50-1000 \mathrm{~Hz}$ is much less than the effect of pressure in the 100-20 kPa interval in the CEV values. Although high frequencies tend to reduce the CEV values in the 100-60 $\mathrm{kPa}$ range, this effect disappears at lower pressures.

To further analyze the effect of pressure, Figure 5 shows the CEV versus pressure error plots at each analyzed frequency. Such error plots show that the CEV reduces with pressure almost linearly. The parameters of the linear fits are summarized in Table 3.

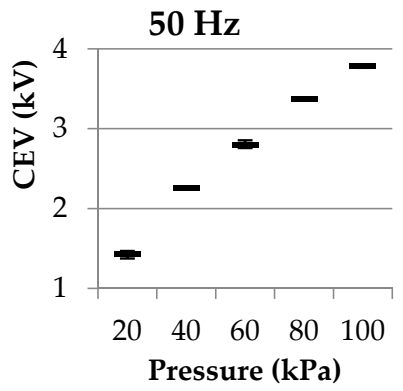

(a)

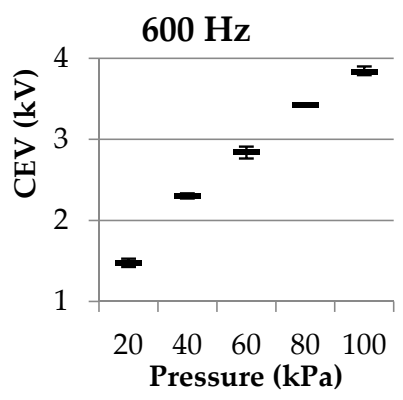

(d)

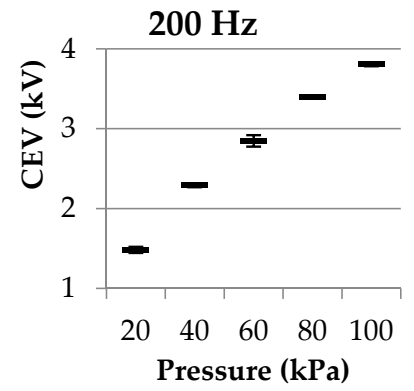

(b)

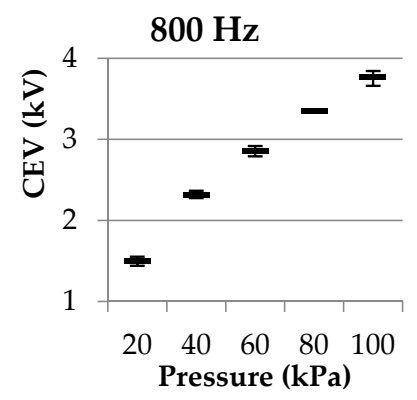

(e)

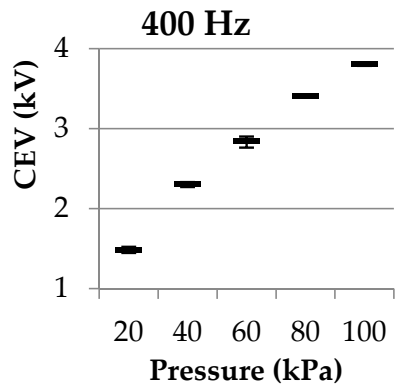

(c)

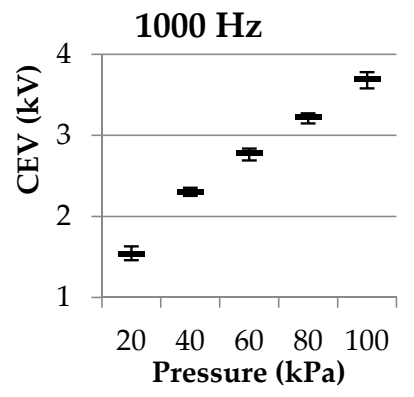

(f)

Figure 5. Experimental results of the rod-to-plane electrode geometry obtained with the CMOS imaging sensor. CEV values $(\mathrm{kV})$ dispersion plot of the three measurements at each point versus pressure (kPa). (a) $50 \mathrm{~Hz}$; (b) $200 \mathrm{~Hz}$; (c) $400 \mathrm{~Hz}$; (d) $600 \mathrm{~Hz}$; (e) $800 \mathrm{~Hz}$; (f) and $1000 \mathrm{~Hz}$. 
Table 3. Linear fit parameters $C E V=C E V_{0}+m \cdot P$, where $C E V_{0}$ is the CEV at zero pressure in Volt, $m$ is the slope in Volt $/ \mathrm{kPa}$ and $P$ is the pressure in $\mathrm{kPa}$.

\begin{tabular}{ccccccc}
\hline \multirow{2}{*}{ Frequency } & \multicolumn{2}{c}{$C E V_{\mathbf{0}}$} & \multicolumn{2}{c}{$\boldsymbol{m}$} & $\boldsymbol{R}^{\mathbf{2}}$ \\
\cline { 2 - 6 } & $\begin{array}{c}\text { Imaging } \\
\text { Sensor }\end{array}$ & $\begin{array}{c}\text { Leakage } \\
\text { Current }\end{array}$ & $\begin{array}{c}\text { Imaging } \\
\text { Sensor }\end{array}$ & $\begin{array}{c}\text { Leakage } \\
\text { Current }\end{array}$ & $\begin{array}{c}\text { Imaging } \\
\text { Sensor }\end{array}$ & $\begin{array}{c}\text { Leakage } \\
\text { Current }\end{array}$ \\
\hline $50 \mathrm{~Hz}$ & 980.5 & 965.9 & 29.182 & 28.908 & 0.9853 & 0.9867 \\
$200 \mathrm{~Hz}$ & 1040.1 & 1031.2 & 28.755 & 28.565 & 0.9845 & 0.9871 \\
$400 \mathrm{~Hz}$ & 1040.0 & 1043.4 & 28.813 & 28.548 & 0.9835 & 0.9839 \\
$600 \mathrm{~Hz}$ & 1033.1 & 1037.5 & 29.084 & 28.765 & 0.9849 & 0.9847 \\
$800 \mathrm{~Hz}$ & 1095.4 & 1093.2 & 27.771 & 27.771 & 0.9820 & 0.9827 \\
$1000 \mathrm{~Hz}$ & 1138.1 & 1138.0 & 26.204 & 26.204 & 0.9863 & 0.9864 \\
\hline
\end{tabular}

$R^{2}$ is the coefficient of determination of linear regression, indicating how well data fits.

Results summarized in Table 3 show a quasi-linear relationship of the CEV versus $P$ plots measured at different frequencies in the $50-1000 \mathrm{~Hz}$ range, according to the high values of the determination coefficient $R^{2}$. These results also show similar values of the $C E V_{0}$ and $m$ parameters for the different frequencies, thus corroborating the low effect of the frequency in the CEV value.

Table 4 compares the CEV values obtained with both sensors.

Table 4. Average difference between the CEV values attained with the CMOS image and the leakage current sensors for each frequency.

\begin{tabular}{cc}
\hline Frequency & Difference \\
\hline $50 \mathrm{~Hz}$ & $1.153 \%$ \\
$200 \mathrm{~Hz}$ & $0.695 \%$ \\
$400 \mathrm{~Hz}$ & $0.388 \%$ \\
$600 \mathrm{~Hz}$ & $0.466 \%$ \\
$800 \mathrm{~Hz}$ & $0.078 \%$ \\
$1000 \mathrm{~Hz}$ & $0.003 \%$ \\
\hline
\end{tabular}

From the values shown in Table 4 it can be observed that both methods have similar sensitivity, whereas the difference between the results attained with the imaging sensor and those with the leakage current sensor decreases with frequency.

\section{Discussion}

The results presented in Figure 4 clearly show that CEV values are mainly affected by ambient pressure. The results plotted in Figure 4 are in accordance with previous studies analyzing gas discharges for specific supply frequencies [7]. This effect is due to the fact that the mean free path between ion collisions is inversely proportional to air density, and thus, a larger number of successful secondary ionizations are produced at a lower pressure, so that partial discharges can occur at lower voltages than the ones required at atmospheric pressure [39].

Regarding the effect of frequency, Linder and Steele [40] studied the effect of frequency on breakdown, proving that breakdown voltage decreases as the operating frequency increases. There are other studies describing that CIV values usually decrease when increasing the frequency, although this effect reduces at lower pressures [10]. This same effect was observed in the experimental results presented in this paper. However, as can be seen in Figure 4, the CEV values at $20 \mathrm{kPa}$ slightly rise when increasing the frequency up to $1000 \mathrm{~Hz}$.

The formation of a larger number of negative corona spots and brighter negative discharges at atmospheric pressure in contrast to what was observed at low pressure as shown in Figure 2a, can be attributed to the fact that at atmospheric pressure a higher voltage is needed to produce a corona; therefore, more spots are suitable for ionization and more molecules are ionized in the process, thus increasing the brightness of the 
discharge [41]. The shape change observed in Figure 2a from a localized and defined to a more diffuse and homogenous corona when lowering pressure, may be due to the fact that at a low pressure, the free path of ionization is larger, so that ionized particles can travel further, thus increasing the active area of ionization. This visual effect of pressure on a corona has also been described in previous studies [42].

The results in Figure $2 \mathrm{~b}$ show that when pressure reduces, the number of streamers also reduces, becoming less diffuse and more localized. This effect was described in [43] using a high-speed photographic camera. In the images presented in this paper, atmosphericpressure streamers appear as a diffuse bluish glow within the gap due to the $32 \mathrm{~s}$ longexposure effect.

To the best of our knowledge, there is a scarcity of publications analyzing in detail the combined effect of variable frequency and variable pressure on visual corona. However, it has been shown that although frequency has no significant visual effect on negative corona (see Figure 2a), there is a slight effect on the streamers of positive corona (see Figure 2b).

The sensibility to detect corona discharges of the image sensor has been tested and compared with that of the leakage current sensor, obtaining very close results, as shown in Figure 4 and in Table 4, where the percentage differences are calculated, which are very low. A similar comparison was performed in [7] where it was also concluded that the imaging method with a CMOS camera has almost the same sensitivity as other sensitive methods for corona detection.

It is noted that a drawback of the detection method based on the CMOS sensor is that it requires partial darkness to operate. However, partial darkness is often found in aeronautics applications since wires and harnesses are often inside troughs, ducts, or conduits whose interior is usually dark. The authors are aware of this drawback, so they are working in the integration of solar-blind imaging sensors, which can also operate under usual sunlight conditions.

\section{Conclusions}

This paper conducted an experimental study to determine the effect of pressure and frequency on visual corona using a CMOS imaging sensor and by measuring the leakage current, proving that both sensing systems present very similar sensitivity, although the imaging sensor allows locating the points where the electrical discharges occur. The study was conducted by analyzing a rod-to-plane air gap in the 20-100 kPa and 50-1000 $\mathrm{Hz}$ intervals, covering most aeronautic applications. The results show that pressure and frequency both have an effect on corona extinction voltage (CEV). CEV increases remarkably with air pressure, but the effect of frequency is lower, causing the CEV to decrease with frequency in the 100-60 kPa pressure range, this effect diminishes with pressure. In addition, a visual description of the effects of pressure and frequency on a corona was performed. The results presented show that the CMOS image sensor has enough sensitivity to be used as a corona detector in low-pressure environments and under a wide range of electrical frequencies. In addition, it was shown that although the difference between the $\mathrm{CEV}$ values found with the CMOS imaging sensor and by analyzing the leakage current is very low, this difference tends to reduce at higher frequencies.

Author Contributions: Conceptualization, J.-R.R. and P.B.-C.; methodology, J.-R.R.; validation, J.-R.R., P.B.-C. and M.M.-E.; formal analysis, M.M.-E.; investigation, J.-R.R. and P.B.-C.; writingoriginal draft preparation, J.-R.R.; writing-review and editing, M.M.-E. All authors have read and agreed to the published version of the manuscript.

Funding: This research was partially funded by Ministerio de Ciencia e Innovación de España, grant number PID2020-114240RB-I00 and by the Generalitat de Catalunya, grant number 2017 SGR 967.

Institutional Review Board Statement: Not applicable.

Informed Consent Statement: Not applicable.

Conflicts of Interest: The authors declare no conflict of interest. 


\section{References}

1. Rui, R.; Cotton, I. Impact of low pressure aerospace environment on machine winding insulation. In Proceedings of the 2010 IEEE International Symposium on Electrical Insulation, San Diego, CA, USA, 6-9 June 2010; pp. 1-5. [CrossRef]

2. Riba, J.-R.; Gómez-Pau, Á.; Moreno-Eguilaz, M. Experimental Study of Visual Corona under Aeronautic Pressure Conditions Using Low-Cost Imaging Sensors. Sensors 2020, 20, 411. [CrossRef]

3. Belijar, G.; Chanaud, G.; Hermette, L.; Risacher, A. Study of Electric Arc Ignition, Behavior and Extinction in Aeronautical Environment, in Presence of FOD; Saint-Exupéry: Toulouse, France, 2017; pp. 1-8.

4. Andrea, J.; Buffo, M.; Guillard, E.; Landfried, R.; Boukadoum, R.; Teste, P. Arcing fault in aircraft distribution network. In Proceedings of the Annual Holm Conference on Electrical Contacts, Denver, CO, USA, 10-13 September 2017; pp. 317-324. [CrossRef]

5. Hao, Z.; Wang, X.; Cao, X. Harmonic Control for Variable-Frequency Aviation Power System Based on Three-Level NPC Converter. IEEE Access 2020, 8, 132775-132785. [CrossRef]

6. Karady, G.G.; Sirkis, M.D.; Liu, L. Investigation of corona initiation voltage at reduced pressures. IEEE Trans. Aerosp. Electron. Syst. 1994, 30, 144-150. [CrossRef]

7. Riba, J.-R.; Gomez-Pau, A.; Moreno-Eguilaz, M. Sensor Comparison for Corona Discharge Detection Under Low Pressure Conditions. IEEE Sens. J. 2020, 20, 11698-11706. [CrossRef]

8. Capineri, L.; Dainelli, G.; Materassi, M.; Dunn, B.D. Partial discharge testing of solder fillets on PCBs in a partial vacuum: New experimental results. IEEE Trans. Electron. Packag. Manuf. 2003, 26, 294-304. [CrossRef]

9. Clean Sky. 9th Call for Proposals (CFP09)_List and Full Description of Topics; Clean Sky: Brussels, Belgium, 2018; pp. 1-354.

10. Esfahani, A.N.; Shahabi, S.; Stone, G.; Kordi, B. Investigation of Corona Partial Discharge Characteristics Under Variable Frequency and Air Pressure. In Proceedings of the 2018 IEEE Electrical Insulation Conference (EIC), San Antonio, TX, USA, 17-20 June 2018; pp. 31-34. [CrossRef]

11. Kang, T.; Ryu, J. Determination of Aircraft Cruise Altitude with Minimum Fuel Consumption and Time-to-Climb: An Approach with Terminal Residual Analysis. Mathematics 2021, 9, 147. [CrossRef]

12. Wheeler, P.; Bozhko, S. The more electric aircraft: Technology and challenges. IEEE Electrif. Mag. 2014, 2, 6-12. [CrossRef]

13. Borghei, M.; Ghassemi, M. Insulation Materials and Systems for More and All-Electric Aircraft: A Review Identifying Challenges and Future Research Needs. IEEE Trans. Transp. Electrif. 2021, 7, 1930-1953. [CrossRef]

14. Mermigkas, A.C.; Clark, D.; Haddad, A.M. Investigation of High Altitude/Tropospheric Correction Factors for Electric Aircraft Applications. In Lecture Notes in Electrical Engineering; Springer: Cham, Switzerland, 2020; Volume 598, pp. 308-315. [CrossRef]

15. el Bayda, H.; Valensi, F.; Masquere, M.; Gleizes, A. Energy losses from an arc tracking in aeronautic cables in DC circuits. IEEE Trans. Dielectr. Electr. Insul. 2013, 20, 19-27. [CrossRef]

16. Woodworth, A.A.; Shin, E.E.; Lizcano, M. High Voltage Insulation for Electrified Aircraft; NASA: Washington, DC, USA, $2018 ;$ p. 11.

17. Shahsavarian, T.; Li, C.; Baferani, M.A.; Cao, Y. Surface discharge studies of insulation materials in aviation power system under DC voltage. In Proceedings of the 2020 IEEE Conference on Electrical Insulation and Dielectric Phenomena (CEIDP), East Rutherford, NJ, USA, 18-30 October 2020; pp. 271-274. [CrossRef]

18. Borghei, M.; Ghassemi, M. Characterization of Partial Discharge Activities in WBG Power Converters under Low-Pressure Condition. Energies 2021, 14, 5394. [CrossRef]

19. Dricot, F.; Reher, H.J. Survey of Arc Tracking on Aerospace Cables and Wires. IEEE Trans. Dielectr. Electr. Insul. 1994, 1, 896-903. [CrossRef]

20. Fabiani, D.; Montanari, G.C.; Cavallini, A.; Saccani, A.; Toselli, M. Nanostructured-coated XLPE showing improved electrical properties: Partial discharge resistance and space charge accumulation. In Proceedings of the 2011 International Symposium on Electrical Insulating Materials, Kyoto, Japan, 6-10 September 2011; pp. 16-19. [CrossRef]

21. Du, B.; Liu, H. Effects of atmospheric pressure on tracking failure of gamma-ray irradiated polymer insulating materials. IEEE Trans. Dielectr. Electr. Insul. 2010, 17, 541-547. [CrossRef]

22. IEEE. The Authoritative Dictionary of IEEE Standards Terms, 7th ed.; IEEE Std 100-2000; IEEE Press: Piscataway Township, NJ, USA, 2000; pp. 1-1362. [CrossRef]

23. Cella, B. On-line Partial Discharges Detection in Conversion Systems Used in Aeronautics; Université de Toulouse: Toulouse, France, 2015.

24. Du, B.X.; Liu, Y.; Liu, H.J. Effects of low pressure on tracking failure of printed circuit boards. IEEE Trans. Dielectr. Electr. Insul. 2008, 15, 1379-1384. [CrossRef]

25. Douar, M.A.; Beroual, A.; Souche, X. Assessment of the resistance to tracking of polymers in clean and salt fogs due to flashover arcs and partial discharges degrading conditions on one insulator model. IET Gener. Transm. Distrib. 2016, 10, 986-994. [CrossRef]

26. Meng, D.; Zhang, B.Y.; Chen, J.; Lee, S.C.; Lim, J.Y. Tracking and erosion properties evaluation of polymeric insulating materials. In Proceedings of the ICHVE 2016-2016 IEEE International Conference on High Voltage Engineering and Application, Chengdu, China, 19-22 September 2016. [CrossRef]

27. Degardin, V.; Kone, L.; Valensi, F.; Laly, P.; Lienard, M.; Degauque, P. Characterization of the High-Frequency Conducted Electromagnetic Noise Generated by an Arc Tracking between DC wires. IEEE Trans. Electromagn. Compat. 2016, 58, 1228-1235. [CrossRef]

28. Babrauskas, V. Research on Electrical Fires: The State of the Art. Fire Saf. Sci. 2008, 9, 3-18. [CrossRef] 
29. Yu, B.; Kang, X.L.; Zhao, Q. An algorithm for gas breakdown voltage prediction in low pressure gap. In Proceedings of the 3rd International Conference on Computer Science and Application Engineering, Sanya, China, 22-24 October 2019. [CrossRef]

30. Owaid, A.; Owaid, A.Y. The Effect of Axial Magnetic Field on The Breakdown Voltage of Air at Low Pressure. Iraqi J. Sci. 2020, 61, 3228-3234. [CrossRef]

31. Riba, J.-R.; Abomailek, C.; Casals-Torrens, P.; Capelli, F. Simplification and cost reduction of visual corona tests. IET Gener. Transm. Distrib. 2018, 12, 834-841. [CrossRef]

32. Kozioł, M.; Nagi, Ł.; Kunicki, M.; Urbaniec, I. Radiation in the Optical and UHF Range Emitted by Partial Discharges. Energies 2019, 12, 4334. [CrossRef]

33. Chen, L.; MacAlpine, J.M.K.; Bian, X.; Wang, L.; Guan, Z. Comparison of methods for determining corona inception voltages of transmission line conductors. J. Electrostat. 2013, 71, 269-275. [CrossRef]

34. Souza, A.L.; Lopes, I.J.S. Experimental investigation of corona onset in contaminated polymer surfaces. IEEE Trans. Dielectr. Electr. Insul. 2015, 22, 1321-1331. [CrossRef]

35. Chai, H.; Phung, B.T.; Mitchell, S. Application of UHF Sensors in Power System Equipment for Partial Discharge Detection: A Review. Sensors 2019, 19, 1029. [CrossRef]

36. He, Z.; Zhu, J.; Zhu, J.; Bian, X.; Shen, B. Experiments and analysis of corona inception voltage under combined AC-DC voltages at various air pressure and humidity in rod to plane electrodes. CSEE J. Power Energy Syst. 2021, 7, 875-888. [CrossRef]

37. Turner, J.; Igoe, D.; Parisi, A.V.; McGonigle, A.J.; Amar, A.; Wainwright, L. A review on the ability of smartphones to detect ultraviolet (UV) radiation and their potential to be used in UV research and for public education purposes. Sci. Total Environ. 2020, 706, 135873. [CrossRef]

38. Wilkes, T.; McGonigle, A.J.; Pering, T.D.; Taggart, A.J.; White, B.S.; Bryant, R.G.; Willmott, J.R. Ultraviolet Imaging with Low Cost Smartphone Sensors: Development and Application of a Raspberry Pi-Based UV Camera. Sensors 2016, 16, 1649. [CrossRef] [PubMed]

39. Naidu, M.S.; Kamaraju, V. High-Voltage Engineering, 6th ed.; McGraw-Hill Education: New York, NY, USA, 2020.

40. Linder, W.; Steele, H. Estimating voltage breakdown performance of high-altitude antennas. In Proceedings of the WESCON/59 Conference Record, San Francisco, CA, USA, 18-21 August 1959; Volume 3, pp. 9-16. [CrossRef]

41. Riba, J.-R.; Gómez-Pau, Á.; Moreno-Eguilaz, M. Insulation Failure Quantification Based on the Energy of Digital Images Using Low-Cost Imaging Sensors. Sensors 2020, 24, 7219. [CrossRef] [PubMed]

42. Lewis, T.G.; Karady, G.G.; Sirkis, M.D. An Analysis of the Frequency Characteristics of Corona Discharge at Low Pressure; Phillips Laboratory, Kirtland Air ForceBase: Albuquerque, NM, USA, 1991.

43. Briels, T.M.P.; van Veldhuizen, E.M.; Ebert, U. Positive streamers in air and nitrogen of varying density: Experiments on similarity laws. J. Phys. D Appl. Phys. 2008, 41, 234008. [CrossRef] 